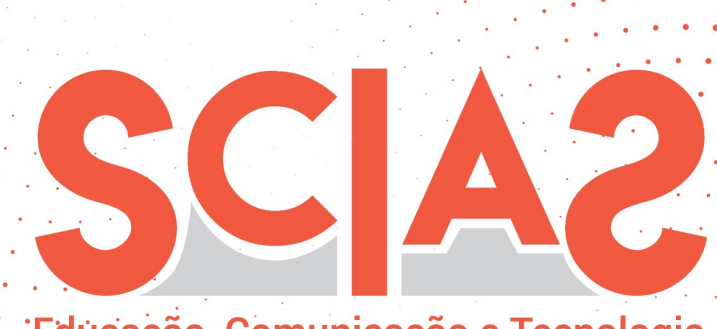

Educuçaçã̉o, Comunicação e Tecnologia

Atribuição BB CY 4.0

\title{
Educação em tempos de redes numa sociedade de consumidores
}

\author{
Mirian Raquel Mion ${ }^{1}$ \\ Marie Jane Soares Carvalho ${ }^{2}$
}

\section{Resumo}

Este ensaio versa sobre a transformação das pessoas em mercadorias acerca da aceleração do tempo, do advento das redes sociais digitais e da comoditização da subjetividade. A partir das reflexões de Sygmunt Bauman, propõe-se a tratar a educação em tempos de redes considerando o cenário descrito da Sociedade de Consumidores, na Modernidade Líquida. A metodologia utilizada para este escrito foi a de revisão bibliográfica em torno dos conceitos que delimitaram a nossa perspectiva de pensar os devires como estratégia a ser adotada na contemporaneidade, apontando para uma necessária coletivização dos sujeitos, no intuito de retomar alianças ou criar novas nas comunidades em que vivemos.

\section{Palavras-chave}

Educação. Redes Sociais Digitais. Subjetividade. Zigmunt Bauman.

Recebido em: 17/02/2020

Aprovado em: 25/06/2020

\footnotetext{
${ }^{1}$ Doutoranda em Informática na Educação na Universidade Federal do Rio Grande do Sul Cientista Social, Mestre em Psicologia Social e Institucional e graduada em Ciências Sociais/UFRGS. Universidade Federal do Rio Grande do Sul.

e-mail: buizmion@hotmail.com

2 Pós-Doutorado - UNED/Madrid (2012). Doutora em Educação/UFRGS (1999). Mestre em Educação (1990). Graduação em Pedagogia (1982). Universidade Federal do Rio Grande do Sul

e-mail: mariejsc@gmail.com
} 


\section{Education in networking times in a consumer society}

\section{Abstract}

This essay deals with the transformation of people into commodities about the acceleration of time, the advent of digital social networks and the commoditization of subjectivity. From the reflections of Sygmunt Bauman, we propose to treat education in times of networks considering the scenario described by the Consumer Society in Liquid Modernity. The methodology used for this writing was the literature review around the concepts that delimited our perspective of thinking becomings as a strategy to be adopted in contemporary times, pointing to a necessary collectivization of the subjects, in order to resume alliances or create new communities in which one lives.

\section{Keywords}

Education. Digital Social Networks. Subjectivity. Zigmunt Bauman. 


\section{Introdução}

Este trabalho tem como inspiração as reflexões teóricas e filosóficas à luz das ideias de Zygmunt Bauman, sociólogo, catedrático emérito de Sociologia nas Universidades de Leeds e Varsóvia, nascido na Polônia, em 1925, e falecido, em 2017, no Reino Unido. Interessa-nos, sobretudo, a comoditizacao da subjetividade e o papel das redes sociais digitais para lançar reflexões sobre educação nestes nossos tempos. Bauman estuda a contemporaneidade ou, como prefere chamar, a Modernidade Líquida, construto que ele cunhou para definir o que seria o mundo globalizado e o impacto das transformações nas mais diversas esferas da vida, como o trabalho, o amor e a vida social. Este escrito, em forma de ensaio, tem como principal referência a obra "Vida para consumo: a transformação das pessoas em mercadoria" (BAUMAN, 2008) aproximando as suas reflexões às de outros teóricos.

As ponderações contidas neste escrito partiram das análises de obras de Zygmunt Bauman e de autores que conversam com sua perspectiva teórica. A partir de um panorama dos assuntos abordados em " 44 cartas de um Mundo Líquido" (2011), sobre seus pensamentos a respeito da contemporaneidade, selecionamos algumas obras para analisar, tais como "Modernidade Líquida" (2001), "Sobre Educação e Juventude" (2013), "Capitalismo Parasitário", "Confiança e Medo na Cidade" (2009), "Comunidade: a busca por segurança no mundo atual" (2003), "Globalização: as consequências humanas" (1999), "Em busca da política" (2000), "Capitalismo Parasitário" (2010), "Vida a Crédito" (2010) e, por fim, a principal obra para este ensaio, Vida para Consumo: a transformação das pessoas em mercadorias (2008).

Para este ensaio vamos tratar em especial sobre os conceitos relacionados à configuração do capitalismo vigente e à forma como ele atua na subjetividade humana e por consequência nas formas de ser e existir. Pelas leituras e análises percebemos que Bauman (2008) recorre a um certo romantismo saudosista de inspiração marxista para falar de coisas do cotidiano e, valendo-se desse recurso, aborda grandes temas. Talvez esteja nesse jeito de abordar a contemporaneidade o motivo da grande aceitação dos seus livros pelo público 
acadêmico e também não acadêmico. O autor assim atualiza conceitos importantes da obra de Marx (1982) como o "fetiche da mercadoria", que seria o hábito de, por ação ou omissão, ignorar ou esconder a interação humana em detrimento do movimento das mercadorias, para o atual "fetiche da subjetividade”, ou seja, o sujeito também se transforma em mercadoria, tornando-nos assim o próprio produto do mercado, de forma pejorativa, ignorando o humano mais uma vez. Essa atualização, advinda da Sociedade de Produtores, possui muitos aspectos a serem pontuados e para explicar como essa transformação se deu, Bauman (2008) destaca, em especial, a velocidade temporal que é impressa em nosso cotidiano, como sendo uma característica influenciadora desse processo; e como as redes sociais digitais colaboram para alterar significativamente as relações sejam elas temporais, sociais ou econômicas.

Constatamos que somos sujeitos atravessados pelas configurações que o mercado nos imprime, transformando-nos em meras mercadorias, comodities, isto é, matérias-primas para serem comercializadas através de redes sociais digitais. O livro traz em suas linhas uma forte crítica ao advento da Sociedade de Consumidores, lembrando que o resultado desse sistema é o surgimento do que ele chama de "consumidores falhos", que seriam aqueles sujeitos que são não consumidores, pois não teriam nenhum valor ou poder aquisitivo, ficando assim à margem da sociedade contemporânea. Bauman (2008) sentencia ainda que as chagas dessa Sociedade de Consumidores, que promete felicidade pelo consumo, seria a desabilitação social e a pobreza ao excluir esses "consumidores falhos" do sistema de consumo.

Aposta-se assim em cativar os públicos cada vez mais precocemente, opta-se por "catequizar" os consumidores cada vez mais cedo, ainda em sua tenra idade, para obter um mercado estendido e longevo, ao ponto de as crianças serem os alvos preferidos dos discursos envolventes do mercado que os perseguem pela vida adulta até chegarem ao túmulo:"Tão logo aprendem a ler, ou talvez bem antes, a 'dependência das compras' se estabelece nas crianças. [...] Numa sociedade de consumidores, todo mundo precisa ser, deve ser e tem que ser um consumidor por vocação" (BAUMAN, 2008, p. 73). 


\section{A rapidez da Modernidade Líquida e a subjetividade}

Na contemporaneidade o que nos rege é o movimento do dia a dia cada vez mais acelerado. A rapidez dos acontecimentos transforma o ambiente em algo imprevisível e de fluxo rápido que está sempre valorizando o que é novidade e não o que seria mais permanente. Isso significa que estamos em constante mudança, mas ela não é fruto de nossa vontade, e sim um imperativo dos nossos tempos. Na contemporaneidade o tempo é fragmentado ou pulverizado, sucedendo uma multiplicidade de "instantes eternos", de rupturas, assumindo uma característica de tempo "agorista". O que se sobressai são os instantes que passamos ocupando uma forma, e não mais a forma em si (Bauman, 2008).

O sociólogo polonês considera que estamos em um momento de transição, saindo da Sociedade de Produtores - na qual se tinha estruturas mais fixas, rígidas e disciplinares, que tinham o espaço, a forma e a territorialidade como pressupostos básicos. E estamos vivenciando o que ele denominou de Modernidade Líquida (BAUMAN, 2008, 2001), uma Sociedade de Consumidores, marcada, metaforicamente, pelo derretimento dessas estruturas, aceleração dos tempos e mudanças contínuas:

Numa sociedade líquido-moderna, as realizações individuais não podem solidificar-se em posses permanentes porque, em um piscar de olhos, os ativos se transformam em passivos, e as capacidades, em incapacidades. As condições de ação e as estratégias de reação envelhecem rapidamente e se tornam obsoletas antes dos atores terem uma chance de aprendê-las efetivamente. (BAUMAN, 2001, p. 7).

A mesma situação acontece com as redes sociais digitais que são estruturas, que interpelam todos os níveis sociais "como as tecnologias midiáticas, são portadores de inovação, não apenas no âmbito tecnológico, mas também no sentido mais amplo do social" (FELICE, 2012, p. 16). Nas redes sociais digitais, nas quais o tempo é muito mais acelerado e o espaço é o do existe-não-existe, são engendradas nossas subjetividades. Assim, as altas velocidades que o contemporâneo já nos exige se aliam aos intensos fluxos e vertigens que deslizam pelas redes sociais digitais a serviço de um mercado consumidor (BAUMAN, 2008). 


\section{O impacto das redes sociais digitais na subjetividade}

O artífice do construto Modernidade Líquida considera avassaladoramente transformador o impacto causado pelas relações mediadas pelas redes sociais digitais e pela subjetividade, ainda que, segundo ele, "dificilmente seria possível culpar a tecnologia pelas novas práticas" (BAUMAN, 2008, p. 8), pois as estruturas sociotécnicas seriam extensões do homem. Sendo assim as redes sociais digitais não são meros instrumentos ou veículos de informação. Sozinhas elas não fariam diferença, é exatamente o encontro entre as redes sociais digitais e a subjetividade que causa essa potente produção (MANSANO, 2009). Produção essa que, segundo Bauman (2008), estaria a serviço, principalmente, de um mercado consumidor que assumiu o papel de principal vigilante dos sujeitos.

Michel Foucault (DREYFUS; RABINOW, 2013) que tratou sobre as diversas tecnologias de vigilância empregadas pela sociedade na docilização dos corpos, alerta para o papel das instituições detentoras de poder, tais como as prisões, as escolas e os hospitais, no processo de controle dos sujeitos com o interesse de estabelecer um tipo de governamento, perfazendo o que ele denominou de biopoder. $\mathrm{Na}$ sociedade contemporânea, as redes sociais digitais são configurações potentes capazes de criar novas formulações entre corpos e mentes, tornando assim uma instituição potente na produção de subjetividade. A cooperação entre pensamentos propiciada por meio dessas redes sociotécnicas tem a potência de subjetivar seus integrantes e assim formar públicos. Essa cooperação é um novo tipo de poder sobre a vida - da vida como memória - esse tipo de poder é chamado por Lazzaratto (2006) de noopoder (poder sobre as almas).

Nas tecnologias, nesse caso, tanto as institucionais quanto as digitais, a confissão é uma característica em comum. Todas elas alcançavam o seu objetivo de controle ao incitar a confissão dos sujeitos sobre a sua própria vida. Atualmente não somente os corpos são alvos do controle, agora também o é pensamento, necessitando assim da atualização das tecnologias de vigilância e 
controle. Nesse caso as redes sociais digitais passaram a compor com as outras tantas tecnologias no sentido de modular as subjetividades:

A confissão difundiu amplamente seus efeitos: na justiça, na medicina, na pedagogia, nas relações amorosas, na ordem mais cotidiana e nos ritos mais solenes; confessam-se os crimes, confessam-se os pecados, confessam-se os pensamentos e desejos [...], suas doenças e suas misérias [...]; fazem-se a si mesmo, no prazer e na dor, confissões impossíveis de serem feitas a outrem e sobre as quais escrevem-se livros. [...] o homem, no Ocidente, tornou-se um animal de confissão. (DREYFUS; RABINOW, 2013 p. 229).

Sendo o mercado o principal beneficiário da enxurrada de confissões feitas agora através das declarações virtuais sobre si disponibilizados via redes sociais digitais.No presente o sujeito torna-se promotor das mercadorias e as mercadorias que promove são, simultaneamente: o produto, seus agentes de marketing, os bens e seus vendedores, todos habitando o mesmo espaço social, conhecido como mercado, como alerta Bauman (2008).A imposição de uma cibervida, que ganhou espaço[...] "com receio de uma 'morte social', aderiram ao imperativo da 'cultura mostre e diga' [...] a nudez física, social e psíquica está na ordem do dia”, mormente haja uma promoção de si constante que publiciza o sujeito a todo o tempo. Ao depositar informações na rede, ao confessar, contando quem é, quem são seus amigos, que lugares frequentam, onde trabalham, estudam, o que compram, quais seus interesses e quem são seus familiares, estariam produzindo e publicizando nas redes sociais digitais esquadrinhando a si mesmos. Rompendo, dessa maneira, a fronteira do que antes ficava no âmbito do privado, pois nossos dados estão cada vez mais públicos (KOEHLER; CARVALHO, 2013), o que possibilita aos operadores do, assim postulado por Bauman (2010), capitalismo parasitário, analisá-los e determinar a inclusão ou exclusão do sujeito do sistema, seja ele de crédito, de recomendação ou social.

O cliente ao ligar para a central, recebe uma recomendação, se for um cliente de primeira classe é enviado para o primeiro lugar da fila de atendimento. Estabelecendo uma certa "vigilância negativa", ao estilo do Big Brother de Orwell ou do tipo panóptico, uma geringonça semelhante a uma peneira que basicamente executa a tarefa de desviar os indesejáveis e manter na linha os clientes habituais. Os "consumidores falhos" são essas ervas daninhas do jardim do consumo, pessoas sem dinheiro, cartões de crédito e/ou entusiasmo por compras, e imunes aos afagos do marketing. Assim, como resultado da 
seleção negativa, só jogadores ávidos e ricos teriam a permissão de permanecer no jogo do consumo. (BAUMAN, 2008, p.11).

\section{A subjetividade como mercadoria, a sua comoditização}

Na Sociedade de Consumidores, não há quem possa se tornar sujeito sem antes virar mercadoria e "ninguém pode manter segura sua subjetividade sem reanimar, ressuscitar e recarregar de maneira perpétua as capacidades esperadas e exigidas de uma mercadoria vendável [...] (BAUMAN, 2008, p. 20). Karl Marx (1982), analisando a Sociedade de Produtores, censurou os economistas da época pela falácia do "fetichismo da mercadoria", que seria o hábito de, voluntário ou involuntário, ignorar ou esconder a interação humana por trás do movimento das mercadorias. Há época em que Marx escrevia sobre o período da Sociedade dos Produtores, os sujeitos eram invisibilizados, pois as mercadorias, através do trabalho e do capital, travavam relações entre si a despeito da mediação humana.

No sistema capitalista globalizado vigente da Sociedade dos Consumidores atualmente, a subjetividade é que é comoditizada e emerge em uma conjuntura que precariza necessidades como a segurança ou a estabilidade e privilegia $o$ atendimento efêmero dos desejos. Bauman descreve que, diferentemente da Sociedade dos Produtores, o que impera na contemporaneidade é a transformação da própria "comoditização" da subjetividade humana como o novo fetichismo da Sociedade dos Consumidores, o "fetichismo da subjetividade", que o modelo do fetiche da mercadoria, o humano, é desapropriado da sua própria posição de humano diante da avidez do mercado: "Se foi o destino do fetichismo da mercadoria ocultar das vistas a substância demasiado humana da sociedade de produtores, é papel do fetichismo da subjetividade ocultar a realidade demasiado comodificada da sociedade de consumidores" (BAUMAN, 2008, p. 20).

No caso da comodificação da subjetividade, o mercado de trabalho é apenas um dos muitos mercados que os sujeitos estão disputando. O que se assemelha em todos esses espaços são as regras que os regem, estendida para todos os espaços de concorrência. Tais regras destinam-se a conscientizar que toda mercadoria, 
aqui, leia-se subjetividade, colocada à venda é para ser consumida por compradores, ou seja, terceiros, que. buscam algo que lhes satisfaça os desejos. O valor dado a tal satisfação está diretamente ligado à credibilidade da promessa de satisfação desses desejos. Como podemos perceber, "é a vez de comprar e vender os símbolos empregados na construção da identidade [...], colocando a 'representação' no lugar daquilo que ela deveria representar, a serem eliminados da aparência do produto final” (BAUMAN, 2008, p. 23).

\section{Os devires e possibilidades da educação na Sociedade de Consumidores}

Historicamente o trajeto que a educação percorreu até os dias de hoje foi preenchido por muitos pontos críticos, até mesmo nós cegos, que precisaram ser desfeitos e refeitos em forma de laços. A periodicidade atribuída à educação por Fava (2012) pode ser objeto de controvérsia; entretanto, ela facilita nosso diálogo sobre a exigência de repensar a educação em um contexto no qual as mediações das relações humanas são feitas pelas redes sociais digitais, e por consequência pelo mercado, alcançando os sujeitos em todos os âmbitos da vida. Fava (2012) traça uma periodicidade longa, na qual a educação se organizou por fases distintas: a primeira é denominada de Educação 1.0 com duração que abarca os primórdios da educação até o surgimento das universidades no século XII; a segunda fase é a da Educação 2.0 com seu auge na industrialização. Em ambas predomina a centralidade da figura do mestre e, em graus distintos de incidência, o treinamento, a memorização e as habilidades manuais. Contemporaneamente, na era digital, a necessidade de pensar e raciocinar é expressada como urgência em responder a problemas que nunca foram antes vivenciados, o que Fava (2012) chama de Educação 3.o, porque a escola passa a necessitar do desenvolvimento da “acuidade mental”. E nessa há uma geração de estudantes que já nasceram imersos em redes sociais digitais.

Para acompanhar esses movimentos intensos e velozes de transformação da Sociedade de Consumidores, a educação necessita também lançar mão de estratégias que contemporizem com a velocidade imposta pela contemporaneidade e as especificidades da aprendizagem. A Educação não está imune aos devires inerentes à Modernidade Líquida tampouco das influências 
das redes sociais digitais na subjetividade dos estudantes. Portanto, para Zygmunt Bauman, a educação nos tempos líquidos não pode mais ser focada em uma ordem social imutável, sólida e com perspectiva de longa duração, e sim deve se preparar para adquirir novos significados diante das atuais circunstâncias sociais, conferindo a ela o mesmo tratamento dos outros temas, como consumo, relações pessoais e éticas, assumindo assim uma perspectiva crítica.

A partir dessa perspectiva, a educação teria que problematizar o contemporâneo jogo duplo de inclusão-exclusão, para o qual as redes sociais servem, ao questionar seus interesses e mensurar o grau de exposição de seus usuários. Se em um primeiro momento, precisamos compor com as redes sociais digitais com vistas a incluí-los e a utilizarmos de seu potencial em uma perspectiva de Educação na Rede, conforme Koehler (2016). Não podemos perder de vista a necessidade de pontuar quanto a suas consequências, assim como Bauman (2008) o fez a partir do pensar sociológico no início da década, tornando de primeira ordem uma discussão crítica e ética sobre os entrelaçamentos entre consumo, redes sociais digitais e subjetividade. E nos deixa nas entrelinhas de seus escritos, como alternativas e devires a ser assumidos pela educação, a urgente retomada de valores presentes nas relações de amizade e solidariedade.

É introduzido na discussão sobre a sociedade de consumidores o culto ao eu. Desta forma, o princípio de responsabilidade se dá agora de outra forma como ocorreu noutros períodos. A moral contemporânea prescreve o cuidado com o "si próprio", essa é a ética moral perpetuada. Cada um sendo responsável a si mesmo e a ética de zelo pelo outro é que pede socorro. Isso se dá porque a relação social na sociedade de consumidores está pautada pelo cálculo, ou o valor profissional que possui, isto é, centralizada em sua utilidade obviamente essa relação é o oposto da amizade e da solidariedade. (BAUMAN, 2008, p. 30).

Como as redes sociais digitais são linhas que perpassam conteúdo, com indução ao consumo, então, enquanto nós, os professores,teríamos como possibilidade trazer um contraponto a essa ideologia vigente, utilizando-se de balizadores semelhantes aos da educação crítica para as mídias (KELLNER; SHARE apud ASSIS, 2019) como uma forma de alfabetizar as pessoas quanto ao real poder e potencial transformador que possuem as redes sociais digitais. Essa abordagem prevê que: 
[...] alfabetização crítica da mídia, que vise a ampliar a noção de alfabetização, incluindo uma ampla variedade de formas de cultura midiática, informações e tecnologias da comunicação e novos meios de comunicação, além de aprofundar o potencial da alfabetização para analisar criticamente relações entre os meios de comunicação e as audiências; a informação e o poder. (ASSIS, 2019, p. 687).

Nesse sentido, o que os autores propõem é a necessidade de viabilizar momentos de reflexão com os alunos quanto ao impacto que as redes sociais digitais têm em nossas vidas, nas nossas subjetividades. Essa possibilidade já é uma maneira de prender a atenção sobre o impacto do consumo. Henningene Gehlen (2012) propõem que se propicie espaços de reflexão e discussão sobre a onipresença quanto ao consumo no nosso cotidiano, nos mais diferentes locais e com diversos públicos diferentes:

Nesse sentido, como parte de uma educação quanto ao consumo, pensamos que rodas de conversa como as que realizamos também poderiam se efetivar em outros espaços escolas, associações de bairro, empresas, etc. -, direcionadas a quem está ou não (super) endividado. $\mathrm{Na}$ verdade, trazer consumo e crédito à discussão da sociedade nos parece urgente para podermos criar alternativas de ser e existir. (HENNINGEN et al., 2012).

Sustentadas pelas reflexões de Zygmunt Bauman na obra "Vida para consumo: a transformação das pessoas em mercadorias”, concluímos que as redes sociais digitais são importantes vetores de informação, mormente, sobre os sujeitos. Destarte, é necessário precaver-se quanto ao impacto que elas causam em nossas vidas. Não se trata de abandoná-las, mas, sim, conscientizar-se sobre os seus usos e o poder sobre nossas mentes. Então, para uma educação em tempos deredes se faz necessário elaborar estratégias capazes de discernir os impactos dos “[...] espetáculos sedutores que fascinam os ingênuos e a sociedade de consumo que envolve a semiótica de um mundo novo de entretenimento, informação e consumo, que influencia profundamente o pensamento e a ação" (KELLNER, 2004, p. 11 apud ASSIS, 2019), sem dispensá-las totalmente, pois elas estão emaranhadas ao nosso cotidiano. Apresentam também alternativas de uso, ou de tipos de redes que privilegiem informações relevantes, para aproveitar o seu potencial agregador para, quiçá, propiciar a retomada do 
espírito comunitário, ao invés de fixar seus usos apenas aos arroubos individualistas e consumistas.

Essas estratégias possibilitam que os envolvidos desenvolvam uma postura mais cética quantos aos conteúdos disponibilizados, e fomentam assim o surgimento de um sujeito mais ético, pois, para além de uma postura individualista, com intuito de apenas sanar seus desejos materiais de consumo, o sujeito pode também estabelecer uma relação mais respeitosa para com o outro. Mesmo sendo ousado, em qualquer tempo, definir o que seria sujeito ético, Bauman (2008) nos alerta que é cada vez mais necessário pensar em uma ética para além do "eu".

Portanto, para isso este ensaio buscou inspiração na relação entre os construtos teóricos do "cuidado de si", que tem sua origem na filosofia da Grécia Antiga e foi revisitado por Michel Foucault nos anos 80, e "cuidado do outro", fomentado por Bauman (2008) como questão da ética a ser urgentemente retomada. O cuidado de si, sem dispor de um cuidado para com o outro, é uma leitura política sobre como deve se guiar a vida. Para experimentar vivências mais éticas, Bauman (2008) aproxima-se do pensamento de Foucault, quando aposta que, para se estabelecer relações mais éticas, menos solitárias e menos individualistas, somente a coletivização dos sujeitos teria força para estabelecer um sentido mais comunitário, assumindo um tom saudosista em seus escritos, almejando um retorno ao convívio em comunidade, com um olhar mais para o passado. Entretanto, o filósofo francês prega sobremaneira uma perspectiva crítica quanto aos processos normatizantes da sociedade e direciona o olhar do leitor para o futuro, privilegiando ações que possibilitem uma estética de novas formas de se viver, através das quais seria possível abrir espaços de liberdade que tornassem possível um modo de viver singular. Opta-se, então, por fazer boas escolhas que não envolvam apenas a si, mas ao outro também, lembrando a proposta de uma "ética da existência". E, nesse caso, para Bauman, uma boa escolha seria retomar o sentido de comunidade, quando sugere dar a devida atenção ao outro. O real sentido de comunidade é o de um agrupamento que compartilha um mesmo "entendimento", e não um "consenso". Isso porque o “consenso" exige disputa de argumentos, já o entendimento está lá, posto desde 
o início, uma rede de relacionamentos em que há confiança, empatia e ajuda (BAUMAN, 2003).

A "ética da existência" é uma proposta que advém da filosofia grega e é revisitada na obra "A hermenêutica do sujeito", curso proferido por Michel Foucault (2006), que extrapola o aforismo grego "conhece a ti mesmo e conhecerás o mundo”, atribuído a Sócrates, que traz a proposta de introspecção e reflexão do homem sobre si como ferramenta para conhecer o mundo também. Nessa perspectiva do âmbito da Modernidade Líquida, o cuidado de si e do outro tem uma proposta mais refinada, pois teríamos que nos preservar, nos cuidar, melhorarmos enquanto sujeitos para conviver com o outro, sem ignorar, e sim, validar as suas opiniões e necessidades, resgatando laços de amizades e de sentido de comunidade.

Portanto, a retomada do cuidar do outro constituiria, na contemporaneidade, um sujeito ético e mais político, no sentido de restabelecer relações que não sejam apenas para suprir desejos incessantes provocados pelo mercado, dando uma conotação mais social e menos individualista ao trato com o outro, pois dividindo soluções, desobriga o sujeito de resolver todas as questões que o infringem sozinho. Sua intenção está em valorizar o cuidado de si, mas para que esses estabeleçam laços mais saudáveis no governo das relações para com o outro (BAUMAN, 2003).

\section{Considerações finais}

As reflexões filosóficas e sociológicas de Zygmunt Bauman sobre consumo, subjetividade, relações sociais, globalização e capitalismo, apresentadas ao longo deste escrito, trouxe luz a esses conceitos. Tais ponderações trazidas pelas leituras das obras ganharam contribuições para o seu entendimento e projeções de devires possíveis a partir da leitura de outros autores que tanto se aproximam quanto se afastam do pensamento do sociólogo polonês. A partir de uma perspectiva crítica, que ganhou repercussão não somente no mundo acadêmico, mas também fora dele, o autor nos convida a pensar em que 
contexto estamos inseridos, sobre nossas limitações e abre possibilidades para pensarmos interlocuções com outros autores, chamados de pós-modernos.

A metáfora da liquidez é escolhida para marcar o derretimento das formas rígidas da Modernidade Sólida, inaugurando o que ele batizou de Modernidade Líquida. Entretanto, esse derretimento não significa falta de rigor do controle sobre os sujeitos, e sim uma certa inconstância, imprevisibilidade e velocidade para as novas formas de poder. Elas acabavam assumindo, por vezes, o aspecto pedagógico e de controle exercidos no passado apenas pelas instituições de poder, como a escola, o hospital, as prisões. Atualmente as redes sociais digitais exercem muito mais vigilância sobre nossas mentes do que sobre nossos corpos, modulando nossa subjetividade conforme as necessidades do mercado, que nos quer consumidor e produto consumível. Os seus usos permitem fazer o jogo de dupla face, tanto o da inclusão no sistema globalizado e capitalista apoiado nas redes de informação, quanto o da exclusão do sujeito no âmbito da Sociedade de Consumidores, caso esses não tenham potencial de consumo. "Vida para Consumo: a transformação das pessoas em mercadorias", bem como as demais obras de Bauman (1999, 2000, 2001, 2003, 2010, 2008, 2013), nos faz refletir sobre uma vida líquida em tempos de redes sociais digitais, globalização, política, mercado, subjetividade, consumo, comunidade e, por consequência, sobre uma educação em tempos de redes.

A educação em tempos de redes sociais digitais na Sociedade de Consumidores, portanto, assume um novo significado diante da aceleração dos tempos, das transformações, da comoditização da subjetividade, o de se estabelecer como um espaço de reflexão quanto aos seus usos, interesses e potencialidades. Faz-se necessário problematizá-las no ambiente educativo, customizando seus usos,com o intuito de resguardar-se, na medida do possível, da vigilância e do puro controle do mercado. Este ensaio não teve como intuito prescrever modos de se pensar sobre as redes sociais digitais, mas sim convidar à reflexão quanto aos seus devires e impactos sobre nossas subjetividades. E pontuar conforme os pressupostos encontrados nas obras de Zygmunt Bauman, e outros autores que colaboram para pensar sua perspectiva de análise, a necessidade de 
reestabelecermos conexões genuínas entre as pessoas, cuidando de nós mesmos e do outro, para formar novas formas de ser e existir na sociedade.

\section{Referências}

ASSIS, Leandro. Mídias digitais, práticas docentes e cotidianos escolares: discussão do paradigma da escola do século XXI a partir da educação crítica para as mídias digitais. 2019. 308f. Dissertação (Mestrado em Mídia e Cotidiano) - UFF, Rio de Janeiro.

BAUMAN, Zygmunt. 44 Cartas do mundo líquido moderno. Rio de Janeiro: Zahar, 2011.

BAUMAN, Zygmunt.Capitalismo parasitário. Rio de Janeiro: Zahar, 2010.

BAUMAN, Zygmunt. Comunidade: a busca por segurança no mundo atual. Rio de Janeiro: Zahar, 2003.

BAUMAN, Zygmunt. Confiança e medo na cidade. Rio de Janeiro: Zahar, 2009.

BAUMAN, Zygmunt. Em busca da política. Rio de Janeiro: Zahar, 2000.

BAUMAN, Zygmunt. Globalização: as consequências humanas. Rio de Janeiro: Jorge Zahar, 1999.

BAUMAN, Zygmunt. Modernidade líquida. Rio de Janeiro: Jorge Zahar, 2001.

BAUMAN, Zygmunt. Sobre educação e juventude. Rio de Janeiro: Zahar, 2013.

BAUMAN, Zygmunt. Vida para consumo: a transformação das pessoas em mercadorias. Rio de Janeiro: Jorge Zahar, 2008.

BAUMAN, Zygmunt. Vida a crédito. Rio de Janeiro: Zahar, 2010.

DREYFUS, Hubert; RABINOW, Paul. Michel Foucault: uma trajetória filosófica: para além do estruturalismo e da hermenêutica. 2. ed. Rio de Janeiro: Forense Universitária, 2013.

FAVA, Rui. Educação 3.o: como ensinar estudantes com culturas tão diferentes. 2. ed. Cuiabá: Carlini e Caniato Editorial, 2012.

FOUCAULT, Michel. A hermenêutica do sujeito. Curso do Collège de France, 1981-1982. São Paulo, Martins Fontes, 2006.

HENNIGEN, Inês; GEHLEN, Gabriela. Com a "vida" no vermelho: psicologia e superendividamento do consumidor. Revista Pesquisas e Práticas Psicossociais, São João del-Rei: UFSJ, v. 7, n. 2, jul./dez. 2012. Disponível em: https://www.ufsj.edu.br/portal2repositorio/File/revistalapip/Volume7_n2/Sumario_7(2).pdf. 
KOEHLER, Cristiane. Interação social em rede e nas redes: contributos para uma educação em rede. UFRGS, Porto Alegre 2016. 278f. Tese de doutorado

KOEHLER, Cristiane; CARVALHO, Marie. O público e o privado nas redes sociais: algumas reflexões segundo Zygmunt Bauman. Espaço Pedagógico, Passo Fundo: UPF, v. 20, n. 2, p. 275-285, jul./dez. 2013. Disponível em: https://www.upf.br/seer/index.php/rep.

LAZZARATTO, Maurice. As revoluções do capitalismo. Rio de Janeiro: Civilização Brasileira, 2006.

MARX, Karl. O capital: crítica da economia política. 7. ed. São Paulo:Boitempo, 1982.

MANSANO, Sônia. Sujeito, subjetividade e modos de subjetivação na contemporaneidade. Revista de Psicologia da Unesp, São Paulo, v. 2, n. 8, p. 110-117. 2009.

MAXIMO, Felice. Redes sociais digitais, epistemologias reticulares e a crise do antropomorfismo social. Revista USP, São Paulo: USP, n. 92 p. 9-19, dez./fev. 2011-2012. Disponível em: http://www.revistas.usp.br/revusp/article/view/34877. 